\title{
INDUÇAO DE MUTAÇÃO VISANDO A REDUÇÃO DE ALTURA DE PLANTA E RESISTÊNCIA ÀS DOENÇAS NO CULTIVAR DE TRIGO (Triticum aestivum L.) IAC-17
}

\author{
A. TULMANN NETO ${ }^{1,4}$; C.E.O. CAMARGO ${ }^{2,4}$; M.C. ALVES ${ }^{3}$, J.L.CASTRO ${ }^{3}$; P.B. GALLO ${ }^{3}$ \\ ${ }^{1}$ Centro de Energia Nuclear na Agricultura - CENAUSP, C.P. 96, CEP: 13400-970-Piracicaba,SP. \\ ${ }^{2}$ Instituto Agronômico de Campinas - IAC, C.P. 28, CEP: 13001-970 - Campinas, SP. \\ ${ }^{3}$ Centro de Informática na Agricultura - CLAGRI/USP, C.P. 9, CEP: 13416-260 - Piracicaba,SP.
}

RESUMO: A reduçăo na altura da planta e obtençăo de resistência d̀s doenças fol expertmentada atraves da indução de mutaç̆o por raios-gama na variedade de trigo (Triticum aestivum $L$.) IAC-17. Sementes foram irradladas com 35 krad e a partir da geraça $M_{2}$ iniciou-se a seleça. Três das linhagens selecionadas foram comparadas com o cultivar original IAC-17, durante três anos, em sete ensaios avançados realizados em vários locais, em condição de sequeiro e irrigaçăo. Os resultados demonstraram a obtençăo de um mutante que apresentou reduçăo na altura da planta, tendência de sofrer menos acamamento e maior resistêncla a ofdio (Erysiphe graminis f. sp. tritici). As demais caracteristicas agronômicas avaliadas, tais como produço de grāos e seus componentes, reaço ao Helminthosporium sativum, causador da mancha das folhas, reaç̄o a Puccinia graminis f. sp. tritici (ferrugem do colmo) e P. recondita (ferrugem da folha), tolerância a aluminio e ciclo permaneceram inalteradas em relação a IAC-17. Os resultados indicaram a utilidade da indução de mutaçōes por raios gama para a correçāo de defeitos de caracteres de herança simples em variedades elites.

Descritores: Raios-gama; mutantes; melhoramento de trigo

\section{REDUCTION OF PLANT HEIGHT AND DISEASE RESISTANCE THROUGH MUTATION BREEDING OF WHEAT (Triticum aestivum L.) IAC-17}

\begin{abstract}
The objective of the present research was to obtain mutants with reduced plant height and resistance to diseases in wheat (Triticum aestivum L.), variety LAC-17, through gamma-irradiation. Seeds were irradlated with gammarays ( 35 krad) and the selection was started in the $M_{2}$ generation. Three selected lines were compared to the control IAC17 during three years, in seven trials carried out in several localities under or without irrigation. One mutant line showed significant reduction in plant height, less lodging and increased resistance to powdery mildew (Erysiphe graminis f. sp. tritici) This mutant also showed the same yield, yleld components, tolerance to aluminium, cycle and reaction to Helminthosporium sativum, Puccinia graminis f. sp. tritici, $P$. recondita as the original variety. The results indicated the usefulness of the mutation breeding method to correct defects of simple inherited characters in oustanding commercial varieties.
\end{abstract}

Key Words: Gamma-rays, mutants, wheat plant breeding

\section{INTRODUÇÃO}

Nos 60 anos dezenas de novas variedades obtidas por indução de mutação foram liberadas aos agricultores, sendo 126 delas para a cultura de trigo (MICKE et al., 1990). Na Itália, esta técnica tem sido utilizada há bastante tempo no melhoramento de trigo $\mathrm{em}$ associação com os métodos tradicionais, e os 11 mutantes registrados como variedades, tiveram um grande impacto econômico (SCARASCIAMUGNOZZA et al., 1993). Dentre as caracteristicas mutadas, neste e em outros países que usaram a indução de mutação em trigo, observa-se que uma das mais frequentes refere-se a redução da altura de planta, mas citam-se também mutantes para ciclo, resistência a doenças e arquitetura de planta. Nestes exemplos, a maioria dos mutantes induzidos apresentaram herança genética simples, embora através de metodologia apropriada, seja possível a seleção para características quantitativas. Mesmo no Brasil, onde existem poucos trabalhos nesta área, relatam-se mutantes para menor altura e resistência às doenças, obtidos por radiação gama (VEIGA et al., 1982a; VEIGA et al., 1982b). OSORIO (1972) cita que um mutante resistente a ferrugem do colmo obtido no Rio Grande do Sul por raios-gama foi intro-

\footnotetext{
${ }^{4}$ Bolsista do CNPq
}

Sci. agric., Piracicaba, 52(2):287-293, mai./ago. 1995 
duzido no programa de melhoramento, resultando em uma nova variedade.

O melhoramento de trigo no Estado de São Paulo permitiu o lançamento de uma série de variedades tais como o IAC-17, com base em vários ensaios de competição de cultivares realizados em solos com e sem alumínio (FELICIO et al., 1983). Essa variedade embora apresentasse tolerância ao $\mathrm{Al}^{+3}$, característica de grande importância no programa de melhoramento, tinha o porte alto e, posteriormente tornou-se suscetível às novas raças das ferrugens do colmo e da folha. Como se sabe, o acamamento está associado com porte alto e pode trazer sérios prejuizos à produção, especialmente na colheita mecanizada.

O objetivo desta pesquisa foi a obtenção de mutantes, através do uso de raios-gama, que apresentassem porte baixo $e$ ou resistência às doenças, especialmente ferrugem do colmo e da folha e que mantivessem as outras características agronômicas da variedade IAC-17 inalteradas .

\section{MATERIAL E MÉTODOS}

Sementes da variedade de trigo IAC-17 foram tratadas com raios gama na fonte de ${ }^{60} \mathrm{Co}$ do CENA/USP em Piracicaba, SP.

Obtenção da geração $M_{1}$ : Baseando-se em ensaio preliminar realizado antes do inicio do experimento, determinou-se que as sementes deveriam ser irradiadas com 35 krad de raios gama para a obtenção da geração $M_{1}$. Esta dose escolhida produzia uma redução de cêrca de 20 \% na altura das plântulas; doses acima desta produziam elevada redução da altura, podendo reduzir muito a sobrevivência e ou acarretar mutações deletérias indesejáveis. Utilizouse a taxa de dose de $129 \mathrm{kR} / \mathrm{hora}$ e teor de umidade de sementes de $12 \%$. Foram irradiadas 170.000 sementes e a semeadura foi feita em 1985 no campo da Estação Experimental do IAC em Tatuí, SP. A geração $M_{1}$ foi colhida pelo sistema massal obtendo-se 1.130 .000 sementes $\mathrm{M}_{2}$.

Obtençăo da geraçăo $M_{2}$ e início da seleção: Das sementes $\mathrm{M}_{2}$ obtidas do tratamento com $35 \mathrm{krad}$, retirou-se uma amostra de 340.000 para a obtenção da geração $\mathrm{M}_{2}$, correspondente a duas vezes o número de sementes irradiadas. Isto foi feito para aumentar a probabilidade de se obter pelo menos um descendente de cada uma das plantas que faziam parte da geração $M_{1}$. Realizou-se a semeadura deste material no mes de maio de 1986 na Estação Expe- rimental de Tatuí, SP. Utilizaram-se fileiras de $5 \mathrm{~m}$ de comprimento, espaçadas uma da outra de $0,20 \mathrm{~m}$. Entre cada 10 fileiras foi plantada uma fileira do cultivar IAC-17 original como controle. Por ocasião do inicio de maturação foram feitas seleções de plantas para altura reduzida de planta e resistência a doenças, especialmente às ferrugens do colmo e da folha. Por ocasião da maturação completa foi colhida uma espiga de cada planta selecionada.

Condução das geraçōes $M_{\mathbf{3}} \in M_{\mathbf{4}}$ : No mês de maio de 1987 as sementes de cada espiga, em geração $M_{3}$, proveniente das plantas selecionadas no ciclo anterior das populaçóes foram semeadas em uma fileira de $1 \mathrm{~m}$ de comprimento; o espaçamento entre fileiras foi de $0,20 \mathrm{~m}$. Entre cada 10 fileiras foi plantada uma fileira da variedade original como controle. Por ocasião da época de maturação foram feitas seleçðes de plantas dentro e entre progênies levando-se em conta os objetivos já mencionados. Escolheu-se de cada planta uma espiga.

No mês de maio de 1988 as sementes de cada espiga em geração $M_{4}$ foram semeadas em uma fileira de $1 \mathrm{~m}$ de comprimento com espaçamento de $0,20 \mathrm{~m}$ entre fileiras; cultivou-se também uma fileira da variedade controle entre cada 10 fileiras. Por ocasiåo da época de maturação foram feitas seleções das melhores linhagens levando-se em consideração os objetivos do trabalho. As linhagens selecionadas foram colhidas e os grãos obtidos foram avaliados no Ensaio Preliminar de Linhagens, no ano seguinte.

As sementes dessas plantas (geração $M_{4}$ ) foram testadas em solução nutritiva contendo 3,6 e 10 $\mathrm{mg} / \mathrm{l}$ de $\mathrm{Al}^{+3}$, conforme método de CAMARGO \& OLIVEIRA (1981). Segundo o critério adotado por estes autores, linhagens ou variedades que mostrarem crescimento de raizes mesmo após o tratamento com $10 \mathrm{mg} / \mathrm{l}$ de $\mathrm{Al}$, são consideradas como tolerantes.

Ensaio preliminar de linhagens: As sementes das linhagens em geração $M_{s}$ oriundas das populações irradiadas foram semeadas em 2 ou 3 fileiras de comprimento, espaçadas uma da outra de $0,40 \mathrm{~m}$, na Estą̧ão Experimental de Tatuí, no mês de maio de 1989. O solo utilizado foi corrigido e adubado e empregou-se irrigação por aspersão.

Por ocasião do início de maturação as linhagens foram avaliadas quanto ao porte, ciclo, resistência a doenças e produção de grãos, selecionandose as melhores para serem testadas no ensaio avançado de linhagens. 
Ensaios avançados de linhagens: Os ensaios avançados foram constituídos de três linhagens selecionadas de IAC-17 provenientes do tratamento com irradiação e do cultivar IAC-17 (controle). A partir de 1990 foram realizados sete ensaios em vários locais, em condição de irrigação ou sequeiro, correspondentes a várias zonas ou regiões para 0 cultivo de trigo. Em condição de sequeiro foram realizados os seguintes ensaios: Maracai (1990 e 1991, Zona A); Candido Mota (1990, Zona A); Capão Bonito (1992, Zona B). Em condição de irrigação por aspersão, foram feitos os seguintes ensaios: Mococa (1991, Zona H); Tatui (1992, Zona D) e Campinas (1992, Zona $\mathrm{H}$ ).

Em todos os experimentos utilizou-se o delineamento estatístico de blocos ao acaso com três repetições. Cada ensaio foi constituido de 12 parcelas, cada uma formada de seis fileiras de $3 \mathrm{~m}$ de comprimento, espaçadas de $0,20 \mathrm{~m}$. Deixou-se uma separação lateral de $0,60 \mathrm{~m}$ entre as parcelas. A semeadura foi feita na base de 80 sementes viáveis por metro de sulco, equivalendo a 1440 por parcela, com uma área útil de colheita de $3,6 \mathrm{~m}^{2}$.

Foram coletados os seguintes dados:

altura das plantas: na época de início de maturação, mediu-se no campo considerando-se como a altura a média de três mediçoes realizadas em locais diferentes dentro de cada parcela, a distância, em centímetros, do nivel do solo ao ápice da espiga, excluindo as aristas.

ciclo da emergência à maturação: fez-se contagens do número de dias decorridos da emergência das plântulas até a maturą̧ão e classificou-se em: precoce $=100-120 \mathrm{dias}$, médio $=121$ a 130 dias e tardio $=$ mais de 130 dias.

ferrugem do colmo e da folha: efetuou-se a avaliaçăo dessas doenças, causadas, respectivamente, por Puccinia graminis f.sp. tritici e $P$. recondita, através de observação geral, em cada planta, no colmo e nas folhas superiores, no estádio de início de maturação, em condições naturais de infecção. Empregou-se a escala modificada de Cobb (SCHRAMM et al., 1974), para avaliação da resistência no Ensaio Internacional de Ferrugem do Trigo de Primavera (International Spring Wheat Rust Nursery). Essa escala vai de 0 a $99 \%$ de área foliar infectada, complementada pelo tipo de reação: $S=$ suscetível (uredossoro grande, coalescente, sem necrose e sem clorose); MS = moderadamente suscetivel (uredossoro médio); $\mathrm{M}=$ intermediário (diversos tipos de reação); $M R=$ moderadamente resistente (uredossoro pequeno), e R = resistente (uredossoro minúsculo, rodeado de áreas necróticas). manchas foliares: avaliou-se esta doença, causada principalmente por Helminthosporium sativum, no estádio de planta adulta, em condições naturais de infecção, empregando-se uma escala (MEHTA, 1978) de 0 a $99 \%$ de área infectada: zero é considerado imune; 1 a $5 \%$ resistente; 6 a $25 \%$, moderadamente resistenie; 26 a $50 \%$ suscetível e 51 a $99 \%$, altamente suscetivel.

Oídio: a avaliação de oídio causado por Erysiphe graminis f.sp. tritici efetuou-se em cada parcela um estádio de planta adulta, em condições naturais de infecção, empregando-se uma escala de 0 a $99 \%$ de área infectada, apresentada por MEHTA (1978), onde 0 é considerado imune; 1 a $5 \%$, resistente; 6 a $25 \%$, moderadamente resistente; 26 a $50 \%$, suscetivel, e 51 a $99 \%$, altamente suscetível.

Ciclo da emergência ao florescimento: efetuouse contagens por parcela individual do número de dias da emergência das plântulas ao pleno florescimento.

Plantas acamadas: considerou-se a porcentagem de plantas acamadas em cada parcela, por avaliação visual próxima à época de maturação, em uma escala que variou de 0 (sem acamamento) até 100\% de acamamento

Produção de grāos: pesou-se, em gramas, a produção total de grãos de cada parcela, a qual foi transformada para quilogramas/hectare

Comprimento da espiga: considerou-se o comprimento médio, em centímetros, de dez espigas colhidas ao acaso em cada parcela, excluindo-se as aristas.

Espiguetas: computou-se o número médio de espiguetas de dez espigas tomadas ao acaso em cada parcela.

Grãos por espiga: considerou-se o número médio de grãos contados em dez espigas tomadas ao acaso, em cada parcela.

Grãos por espigueta: dividiu-se o número total de grãos de dez espigas coletadas ao acaso, em cada parcela, pelo número total de suas espiguetas.

Peso de cem grãos: levou-se em conta o peso, em gramas, de cem grãos tomados ao acaso na produção total de cada parcela.

Estas últimas cinco características foram avaliadas somente no ensaio de Tatui em 1992.

Análises estatísticas: Os dados de produção de grãos e altura de plantas foram inicialmente analisados, separando-se os ensaios irrigados dos de sequeiro.Uma vez observada a homogeneidade de variâncias entre as duas condiçóes e dada a uniformidade do planejamento nos sete ensaios avançados, optou-se pela execução e apresentação dos 
resultados de um análise conjunta para as duas condiçชes.Através dessa análise de variância, objetivou-se testar, através de teste $\mathrm{F}$ a existência ou inexistência de efeitos dos fatores genótipo, irrigação e ensaios, bem como a interação genótipo $x$ irrigaçåo. Quando verificada a rejeiçâo da hipótese de nulidade para o efeito de genótipos, comparou-se cada linhagem selecionada com o cultivar IAC-17 (controle), através do teste de Dunnett.

$A$ análise do comprimento da espiga, número de espiguetas por espiga, número de grãos por espiga, número de grãos por espigueta e peso de 100 grãos, anotados no ensaio de Tatui em 1992, foi feita seguindo o modelo adotado no planejamento, que foi o de um experimento aleatorizado $\mathrm{cm}$ blocos. As médias das linhagens selecionadas foram comparadas com as do controle (IAC-17) através do teste de Dunnett.

\section{RESULTADOS}

Obtençăo de linhagens selecionadas de $\mathrm{AC}$-17: A seleçấo para obtenção de linhagens, de acordo com os objetivos e critérios descritos anteriormente, começou a ser efetuada na geração $\mathrm{M}_{2}$. Em 1986 foram selecionadas 259 plantas, observando-se suas progênies (geração $\mathrm{M}_{3}$ ) no campo em 1987. Destas, 197 seguiram em observação em 1988 (geração $\mathrm{M}_{4}$ ), elegendo-se 90 destas para o ensaio preliminar rea- lizado em 1990. Deste ensaio preliminar, resultaram as três linhagens que foram incluidas nos ensaios avançados de produção.

Análise conjunta da produção de grăos e altura de plantas e resultados do acamamento médio dos ensaios avançados de linhagens: Os resultados da análise conjunta dos sete ensaios avançados de produção, em condições de irrigação e sequeiro, encontram-se na TABELA 1.

Observa-se que, os coeficientes de variação foram bastante aceitáveis. Nos dois casos o valor de F para ensaios foi significativo, indicando uma influência do ano ou local. Para a produção de grãos, os genótipos não diferiram significativamente e apresentaram o mesmo comportamento em condiçбes de irrigação ou sequeiro, como indicado pelo valor não significativo de $\mathrm{F}$ (genótipo $\mathrm{x}$ irrigaçấo). Entretanto, houve diferenças na produção, quando os genótipos foram cultivados em condições de irrigação ou sequeiro (valor de F significativo). A mesma situação ocorreu para a altura de plantas, no que se refere a interações e influência da irrigação. Observa-se que houve uma tendência de redução na altura das plantas das linhagens selecionadas, entretanto, apenas a linhagem 5 apresentou valor significativamente menor do que o controle. As linhagens L-4 e L-5 mostraram tendência de sofrer menos acamamento (27\% em média) do que a variedade IAC-17 (40\%).

TABELAA 1. Médias ${ }^{1}$ de produção de grãos, altura das plantas e acamamento de 3 linhagens selecionadas do tratamento com sementes irradiadas em comparação com a variedade IAC-17 original ${ }^{2}$.

\begin{tabular}{lccc}
\hline Genótipos & $\begin{array}{c}\text { Produção de gråos } \\
(\mathrm{kg} / \mathrm{ha})\end{array}$ & $\begin{array}{c}\text { Altura da planta } \\
\text { (cm) }\end{array}$ & $\begin{array}{c}\text { Acamamento } \\
\%\end{array}$ \\
\hline IAC-17 & 2.442 & $91 \mathrm{a}$ & 40 \\
L-3 & 2.320 & $87 \mathrm{a}$ & 38 \\
L-4 & 2.550 & $86 \mathrm{a}$ & 28 \\
L-5 & 2.609 & $83 \mathrm{~b}$ & 26 \\
F (Genót.) & $1,87 \mathrm{~ns}$ & $4,45^{*}$ & \\
F (Genót. x Irrigação & $1,42 \mathrm{~ns}$ & $0,52 \mathrm{~ns}$ & \\
F (Irrigaçåo) & $532,33^{* *}$ & $113,64^{* *}$ & $31,76^{* *}$ \\
F (Ensaios) & $2,91 *$ & 4,51 & \\
CV\% & 10,76 & 4
\end{tabular}

1 Médias de 7 ensaios realizados em vários anos e locais em condiçóes de irrigação e sequeiro.

2 As médias das linhagens foram comparadas com as do cultivar IAC-17 pelo teste de Dunnett. Médias das linhagens seguidas pelas mesmas letras, nåo apresentam diferença estatisticamente significativa. 


\section{Outras caracteristicas agronómicas dos genótipos avaliados nos ensaios avançados de linhagens}

Na TABELA 2 observa-se a incidência mínima e máxima de mancha foliar, oídio, ferrugem da folha e do colmo, observada nos ensaios onde houve a ocorrência destas doenças, segundo a escala descrita anteriormente. Segundo o critério adotado, todos os genótipos foram suscetiveis a manchas foliares, por apresentarem pelo menos em um ensaio porcentagem de área infectada entre 26 a $50 \%$. No que se refere a oidio, a linhagem L-5 pode ser considerada como moderadamente resistente, enquanto que IAC-17 e as linhagens $\mathrm{L}-3$ e $\mathrm{L}-4$, suscetiveis. Para ferrugem da folha e do colmo, baseandose no maior valor observado (10S), todos os genótipos podem ser considerados como suscetíveis, ña se observando portanto vantagens na seleção.
Na TABELA 3 observam-se os dados relacionados aos componentes da produção, avaliados no ensaio realizado em Tatui, sob condiçáo de irrigacão, em 1992. Apesar de se notar uma tendência das linhagens apresentarem valores maiores que os do controle, apenas para a linhagem $L-4$, no que se refere ao comprimento de espiga, a média obtida foi significativamente maior que a de IAC-17.

O comprimento médio das raizes das linhagens selecionadas e de IAC-17, medido 72 horas de crescimento nas soluçôes nutritivas completas, que se seguiu a $\mathbf{4 8}$ horas de crescimento nas soluçōes de tratamento contendo três concentrações de alumínio, encontra-se na Tabela 4. Segundo o critério que vem sendo adotado para tal tipo de avaliação (CAMARGO \& OLIVEIRA, 1981), como citado anteriormente, todos os genótipos avaliados podem ser considerados como tolerantes pois mostraram crescimento das raizes mesmo aposs o tratamento em soluçб̋es contendo $10 \mathrm{mg} / \mathrm{l}$ de alumínio.

TABELA 2. Incidência minima e máxima de doenças nas linhagens selecionadas e na variedade original IAC17 , avaliada nos sete ensaios de acordo com as escalas utilizadas.

\begin{tabular}{|c|c|c|c|c|}
\hline \multirow[t]{2}{*}{ Genótipos } & \multirow[t]{2}{*}{ Mancha da folha } & \multirow[t]{2}{*}{ Oidio } & \multicolumn{2}{|c|}{ Ferrugem } \\
\hline & & & Folha & Colmo \\
\hline IAC-17 & $20-40$ & $10-40$ & $5 S-10 S^{\prime \prime}$ & $5 S-10 S$ \\
\hline L-3 & $10-40$ & $0-30$ & $5 S-10 S$ & $0-10 s$ \\
\hline$L-4$ & $20-40$ & $0-30$ & $0-10 S$ & $0-10 S$ \\
\hline L-5 & $10-40$ & $0-20$ & $0-10 S$ & $0-10 S$ \\
\hline
\end{tabular}

: reação Suscetivel (uredossoro grande, coalescente, sem necrose e sem clorose).

Năo se julgou necessária a apresentaçăo dos ciclos dos diferentes genótipos, pois embora houvesse uma variaçăo de precoce (100 dias) a médio (110 dias), de acordo com o local e ano do experimento, esta variação também foi observada para a variedade IAC-17, indicando que as linhagens năo diferiram do controle no que se refere ao ciclo.

\section{DISCUSSÃo}

Existem vários métodos para a condução de populaçōes provenientes de tratamentos com mutagênicos, visando-se a seleçăo de mutantes (KONZAK \& MIKAELSEN, 1977). Através de um dos métodos possiveis retira-se de cada planta $M_{1}$, uma semente para a constituição da geraçăo $\mathrm{M}_{2}$.

Entretanto, para que tal método se mostre eficiente, há a necessidade de se tratar grande número de sementes (UKAI \& YAMASHITA, 1974).
No presente trabalho, irradiou-se um grande número de sementes (170.000), o que permitiria a utilização deste processo. Entretanto, para se evitar o grande trabalho de se colher uma semente de cada planta sobrevivente, como alternativa, o que se fez foi retirar-se uma amostragem que correspondeu ao dobro do número de sementes tratadas para a constituição da geração $\mathrm{M}_{2}$, onde se iniciou a seleção. Como se observou pelos resultados obtidos, tal método possibilitou a seleção de pelo menos um dos tipos de mutantes desejados (redução de altura de planta).

Os dados obtidos para a altura indicaram que em pelo menos um caso (linhagem L-5) houve a obtençä́o de um mutante com altura de planta reduzida e menor \% de acamamento, confirmando o resultado das seleçóes feitas anteriormente. A produção de grấos desta linhagem foi semelhante a da variedade original, não se observando a vantagem da menor $\%$ de acamamento, que deveria causar menores 
TABELA 3. Dados médios' referentes a comprimento da espiga, número de espiguetas por espiga, número de grãos por espigueta e peso de cem grãos das 3 linhagens selecionadas do tratamento com sementes irradiadas e de IAC-17, avaliados no ensaio de Tatui em 1992.

\begin{tabular}{llllll}
\hline \hline Genótipos & $\begin{array}{c}\text { Comprimen- } \\
\text { to da espiga } \\
\mathbf{c m}\end{array}$ & $\begin{array}{c}\text { Espiguetas } \\
\text { por espiga } \\
\mathbf{n}^{\circ}\end{array}$ & $\begin{array}{c}\text { Gráos } \\
\text { por espiga } \\
\mathbf{n}^{\circ}\end{array}$ & $\begin{array}{c}\text { Gráos } \\
\text { por espigueta } \\
\mathbf{n}^{\circ}\end{array}$ & $\begin{array}{c}\text { Peso de } \\
\text { cem grãos } \\
\mathrm{g}\end{array}$ \\
\hline LAC-17 & $7,69 \mathrm{a}$ & 18,4 & 27,7 & 1,49 & 4,49 \\
L-3 & $8,07 \mathrm{a}$ & 19,0 & 30,2 & 1,58 & 4,59 \\
L-4 & $8,74 \mathrm{~b}$ & 19,8 & 32,7 & 1,64 & 4,74 \\
L-5 & $\mathbf{8 , 1 9 \mathrm { a }}$ & 19,0 & 30,6 & 1,61 & 4,60 \\
\hline F(Genót.) & $6,51^{* *}$ & $2,13 \mathrm{~ns}$ & $2,67 \mathrm{~ns}$ & $1,25 \mathrm{~ns}$ & $3,28 \mathrm{~ns}$ \\
CV\% & 3,61 & 3,65 & 7,17 & 6,30 & 2,13 \\
\hline \hline
\end{tabular}

As médias das linhagens foram comparadas com as do cultivar IAC-17 pelo teste de Dunnett. Médias das linhagens seguidas pelas mesmas letras não apresentam diferença estatisticamente significativa.

TABELA 4. Comprimento médio das raizes das linhagens selecionadas e de IAC-17 (original) medido após 72 horas de crescimento na solução nutritiva completa, que se seguiu de crescimento na solução de tratamento contendo quatro concentrações de alumínio.

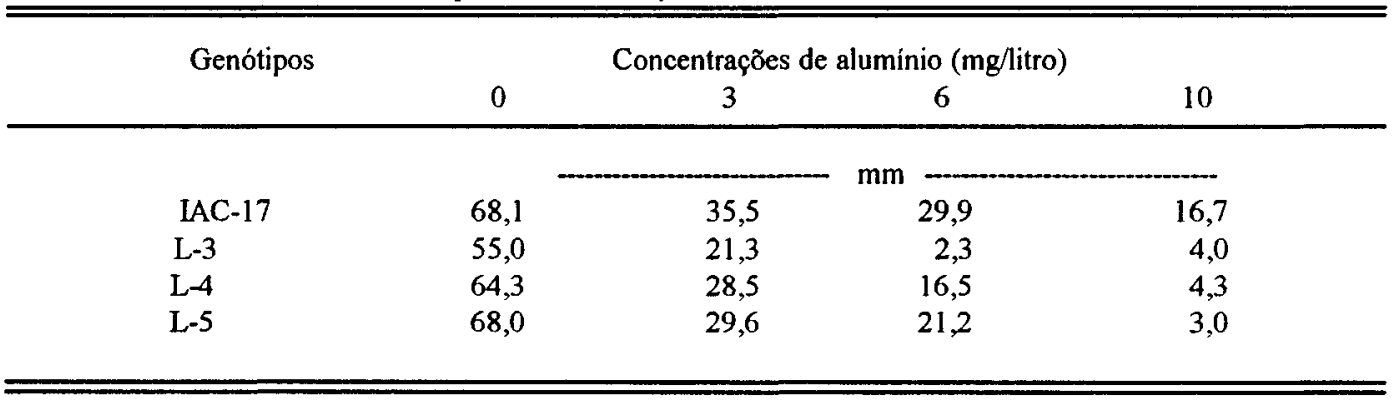

perdas de produção. Mas, deve-se realçar que neste experimento a colheita foi manual e não mecânica, onde se espera que ocorram estas perdas. Os menores valores de altura observados para as outras linhagens, não foram verificados a nível estatístico. $\dot{E}$ de importância relatar-se que a redução observada na altura na linhagem L-S não foi acompanhada de outras mudanças drásticas, pois esta linhagem manteve além da produção de grãos, a mesma reação às doenças, ciclo, tolerância a alumínio e componentes da produção, do que a variedade IAC-17 da qual foi originada. Esta aliás é uma das vantagens que tem sido relatadas para o uso de indução de mutação, onde é possivel modificar-se um "defeito" em determinada variedade, sem se alterar as suas demais caracteristicas básicas (MICKE et al, 1987). Devese entretanto reconhecer que não é sempre que isto ocorre, havendo exemplos inclusive em trigo, em que embora houvesse a obtenção do mutante procurado, houve também a ocorrência de outras mutações que modificaram muito a constituição genética, impossibilitando a substituição do cultivar original pelo mutante. Isto ocorreu por exemplo no Brasil, quando se obteve mutantes de porte baixo em IAC-5 (VEIGA et al, 1982a), mas que perderam a tolerância a alumínio apresentada por tal cultivar.

Apenas em uma das linhagens $\mathrm{L}-4$ houve alteração significativa em um dos componentes da produção, observando-se aumento no comprimento da espiga em relação a variedade original.

No que se refere à resistência a doenças, apenas para a linhagen L-5, obteve-se um aumento na resistência a oidio, em relação a variedade original. Para as demais doenças, a reação das linhagens selecionadas foi a mesma que a de IAC-17. Como nas etapas iniciais de seleção as linhagens apresentaram melhor reação às ferrugens do colmo e da fotha, pode ter ocorrido com o passar dos anos, o apa- 
recimento de novas raças o que explicaria os resultados obtidos. Apesar dos vários sucessos obtidos em indução de mutação visando-se resistência a doenças, principalmente em cereais (KONZAK, 1984), reconhece-se também que há vários casos de insucesso, devido à ocorrência de novas raças, método inadequado de manejo das populações e efeitos pleiotópicos que acompanham a mutação (MICKE et al., 1987).

\section{CONCLUSÕES}

A irradiação de sementes da variedade de trigo IAC-17 e subsequente seleção nas gerações seguintes possibilitou a obtenção de uma linhagem mutante com altura menor de planta, tendência a de sofrer menos acamamento e maior resistência a oídio. Outras características agronômicas, tais como produção e seus componentes, reação às doenças, tolerância a alumínio e ciclo, não sofreram mudanças. Portanto, defeitos em caracteres com base genética simples de cultivares elites são passiveis de serem corrigidos através do uso da técnica de indução de mutação com raios gama, seguida por métodos convencionais de teste e seleção.

\section{REFERÊNCIAS BIBLIOGRÁFICAS}

CAMARGO, C.E.O.; OLIVEIRA, O.F. Tolerância de cultivares de trigo à diferentes níveis de alumínio em solução nutritiva e no solo. Bragantia, Campinas, v. 40, p. 21-31, 1981.

FELICIO, J.C.; BARROS, B.C.; CAMARGO, C.E.O.; BAR, W.H. Maracai (IAC-17) e Xavantes (IAC-18): cultivares de trigo para oEstadode São Paulo. Bragantla, Campinas, v. 42, p. $15-25,1983$.

KONZAK, C.F. Role of induced mutations. In: VOSE, P.B.; BLIXT, S.G.,(Ed.) Crop breeding: a contemporary basis. Oxford: Pergamon Press, 1984. cap. 9, p.216-292.

KONZAK, C.F.; MIKAELSEN, K. Selecting parents and handling the M1-M3 generations for the selection of mutants. In: INTERNATIONAL ATOMIC ENERGY AGENCY, (Ed.) Manual on mutation breeding. Vienna, 1977. p. 125-138.

MEHTA, Y.R. Doenças do trigo e seu controle. São Paulo: Ceres, $1978.190 \mathrm{p}$.
MICKE, A.; DONINI, B.; MALUSZYNSKI, M. Induced mutations for crop improvement. Viena: International Atomic Energy Agency, 1990. 41 p. (Mutation Breeding Review, 7).

MICKE, A.; DONINI, B.; MALUSZYNSKI, M. Induced mutations for crop improvement: a review. Tropical Agriculture, Trinidad, v. 64, n.4, p.259-278, 1987.

OSORIO, E.A. El mejoramiento genetico del trigo en el Brasil y las posibilidades de utilizacion de mutaciones inducidas. In: INTERNATIONAL ATOMIC ENERGY AGENCY, (Ed.). Induced mutations and plant improvement. Vienna, 1972, p. 435-445.

SCHRAMM, W.; FULCO,W.S.; SOARES, M.H.G.; ALMEIDA, AM.P.Resistência de cultivares de trigo em experimentação ou cultivo no Rio Grande do Sul, às principais doenças füngicas. Agronomia Sulriograndense, Porto Alegre, v. 10, n.1, p. 31-39, 1974.

SCARASCIA-MUGNOZZA, G.T.; D'AMATO, F.D.; AVANZI,A; BAGNARA,D.; BELLI, M.L.; BOZZINI, A; BRUNORI, A; CERVIGNI, T.; DEVREUX, M.; DONINI, B.; GIORGI, B.; MARTINI, G.; MONTI, L.M.; OSCHINI, E.; PORRECA, G.; ROSSI, L.. Mutation breeding for durum wheat (Triticum turgidum ssp durumDesf.) improvement in Italy. Vienna:International Atomic Energy Agency, 1993.28 p. (Mutation Breeding Review, 10).

UKAI, Y.; YAMASHITA,A.. Theoretical considerations on the problems of screening of mutants. Bulletin of the Institute of Radiation Breeding, Japan, v. 3: p. 1-144, 1974.

VEIGA, A.A.; CAMARGO, C.E.O.; FELICIO, J.C.; BARROS, B.C.; TULMANN NETO, A; MENTEN, J.O.M.; ANDO, A. Evaluation of three induced short culm wheat mutants obtained in Brazil. In: INTERNATIONAL ATOMIC ENERGY AGENCY, (Ed.) Semi dwarf cereal mutants and their use in cross breeding. Vienna, 1982a. p. 47-51.

VEIGA, AA; FELICIO, J.C.; CAMARGO, C.E.O., BARROS, B.C.,TULMANN NETO,A; MENTEN, J.O.M.; ANDO, A. Avaliação de mutantes de trigo (Triticum aestivum) obtidos por radiações gama resistentes à ferrugem do colmo (Puccinia graminis tritici). Energia Nuclear e Agricultura, Piracicaba, v. 4, n. 1, p. 59-70, 1982b.

Recebido para publicação em 29.08.94

Aceito para publicação em 08.08 .95 